\title{
HOW REASONABLE ARE ASSUMPTIONS USED IN THEORETICAL MODELS?: COMPUTATIONAL EVIDENCE ON THE LIKELIHOOD OF TRADE PATTERN CHANGES
}

\author{
Lisandro Abrego \\ Raymond Riezman \\ John Whalley
}

Working Paper 8169

http://www.nber.org/papers/w8169

\author{
NATIONAL BUREAU OF ECONOMIC RESEARCH \\ 1050 Massachusetts Avenue \\ Cambridge, MA 02138 \\ March 2001
}

We are grateful to the Centre for the Study of Globalisation and Regionalisation at the University of Warwick, the ESRC, and the Henry B. Tippie College of Business at the University of Iowa for support; and to Scott Page, Carsten Kowalczyk, Carlo Perroni, Ben Zissimos, Ben Lockwood, and Ted To for discussions. An earlier version of this paper was presented at a seminar at Warwick in March 2000. The views expressed herein are those of the authors and not necessarily those of the National Bureau of Economic Research.

(C) 2001 by Lisandro Abrego, Raymond Riezman and John Whalley. All rights reserved. Short sections of text, not to exceed two paragraphs, may be quoted without explicit permission provided that full credit, including (C) notice, is given to the source. 
How Reasonable Are Assumptions Used in Theoretical Models?:

Computational Evidence on the Likelihood of Trade Pattern Changes

Lisandro Abrego, Raymond Riezman and John Whalley

NBER Working Paper No. 8169

March 2001

JEL No. F10, F13, F15

\begin{abstract}
$\underline{\text { ABSTRACT }}$
This paper seeks to contribute to discussion of the reasonableness of sometimes seemingly innocent assumptions used in theoretical trade models that the direction of trade is both predetermined for each good for each country and fixed. Here, we provide computational evidence as to the reasonableness of this assumption. We consider a simple three-country, three-good, pureexchange model with CES preferences. We compute free trade competitive equilibria, three-country non-cooperative Nash equilibria, and customs union equilibria for randomized parameterizations, and find that trade patterns change in around $35 \%$ of the cases between free trade and customs union equilibria. In three-country Nash and customs unions comparisons trade patterns change roughly $40 \%$ of the time. We evaluate alternative cases, including with different numbers of randomizations in the parameter space. Results remain robust, reinforcing our conclusion that the assumption of unchanged trade pattern changes, common in theoretical analysis, does not have firm numerical support in the cases we consider.
\end{abstract}

Lisandro Abrego

University of Warwick

John Whalley

Universites of Warwick and Western Ontario and NBER
Raymond Riezman

University of Iowa 


\section{INTRODUCTION}

This paper reports computational evidence that suggests that, despite assumptions made in theoretical analysis to the contrary, changes in the pattern of trade are surprisingly likely to occur in three or more country trade models that compare various tariff equilibria and free trade. Early customs unions models (Viner (1950), Meade (1955), Lipsey (1970), Berglas (1979) and Lloyd (1982)) assumed fixed trade patterns, sometimes implicitly rather than explicitly. Berglas (1979) is explicit when he states on page 329 that "We deliberately ignored the possibility that the formation of a customs union would extinguish or reverse the flow of trade..." The more modern regional trade agreements literature, which focuses on general equilibrium and optimal tariffs, restricts model structures in ways which effectively rule out changing trade patterns. Kennan and Riezman (1990), Syropoulos (1999), and Kose and Riezman (2000) all assume symmetry, and have fixed trade patterns as a result. Krugman (1991) uses symmetry and monopolistic competition (which ensures complete specialization) with the result that trade patterns will also not change across equilibria. The assumption of fixed trade patterns is also pervasive in the tariff retaliation literature (Johnson (1953-54) and Kennan and Riezman (1988).) Our analysis suggests that in environments with three or more countries and three or more goods, and where asymmetries of size and/or preference patterns enter, trade patterns can frequently change across equilibria.

This finding brings into question the robustness of some of the results in the theoretical literature on both regional trade agreements and optimal tariffs since these are based on the assumption that trade flows by commodity and by country remain unchanged in direction as different equilibria are compared. The wider implications are both that it is possible to assess the reasonableness of their assumptions using the methods we outline, and that in extending two-country results in the literature to models with three or more countries and three or more goods one has to deal with the possibility that a move from free trade to tariff equilibrium involves changing trade patterns.

In making our computations we consider a simple three-country, three-good, pure-exchange economy ${ }^{1}$ with CES preferences since it is a parsimonious, trans-

\footnotetext{
${ }^{1}$ Models with production add more parameters to the model specification, but do not change the basic feature that country behaviour towards each other in terms of optimal tariff setting, is determined by elasticities of excess demand functions. These, particularly in turn, reflect underlying demand and supply functions. If supply functions are perfectly inelastic demand functions
} 
parent structure within which to conduct our analysis. The strategic variables we consider in the non-cooperative games are country tariff rates. We consider random draws on possible model parameterisations. For each generated parameterization, we compute a free trade equilibrium, a customs union equilibrium in which the two member countries play non-cooperatively against the third country, and a three-country, non-cooperative Nash equilibrium ${ }^{2}$. Instead of imposing a trade pattern on any equilibrium considered in the model, as is usually done in the literature, we allow it to be endogenously determined as part of each equilibrium computation.

We find trade pattern changes in about $35 \%$ of cases when comparing free trade and customs union equilibria, and around $40 \%$ of cases for comparisons between three-country Nash equilibria and customs unions. We believe that these frequencies would increase as more goods and countries are added, but we have not considered such cases due to the computational complexities involved. We conclude that while assumptions of unchanged directions of trade in theoretical models may be convenient or even necessary for analytical tractability, they are not supported by computational experience for the models and functional forms we consider here.

\section{THE COMPUTATIONAL MODEL}

To analyze the likelihood of trade pattern changes, we specify functional forms, parameter values, and endowments and use numerical simulation techniques applied to a three-country trade model. We use a procedure of random selection of parameter values; randomly drawing preference share parameters, elasticity parameters and endowments from pre-specified admissible ranges. For each model specification generated in this way we compute three types of equilibria; a free trade equilibrium, a three country non-cooperative Nash equilibrium, and a two country customs union equilibrium with the member countries jointly playing Nash against the third country. For each parameterization we determine whether or not trade patterns change in comparisons across these equilibria, and on this basis compute sample frequencies for trade pattern changes.

determine excess demand elasticities. Randomizing over preference function parameters is thus sufficient to generate an implicit randomization over excess demand function elasticities

${ }^{2}$ We assume uniqueness of these equilibria. We have not encountered any instances of multiplicity in our model solutions, although there are no guarantees, even with the simple structures we use, that this will be so. (see Kehoe 1980). 


\subsection{Model Structure}

In the three-country, three-good, pure exchange general equilibrium model, each country has a single representative consumer who has endowments of the three goods and a utility function of the form

$$
U^{i}=U^{i}\left(X_{1}^{i}, X_{2}^{i}, X_{3}^{i}\right) \quad(i=1 \ldots 3)
$$

For any good $j$, we define the seller's price (i.e. net of tariff prices) as $P_{j}$, and allow each country to impose tariffs at rate $t_{j}^{i}$ on good $j$ imported by country $i$. Tariffs are set to zero on any good exported by country $i$. This implies that internal (gross of tariff prices) for good $j$ in any other country $i$ are

$$
P_{j}^{i}=\left(1+t_{j}^{i}\right) P_{j}
$$

Tariff revenues collected by country $i$ are given by

$$
T^{i}=\sum_{i=1}^{3} t_{j}^{i} P_{j}\left[\max \left(\left(X_{j}^{i}-\bar{E}_{j}^{i}\right), 0\right)\right]
$$

and the income of the country $i$ is given by

$$
I^{i}=\sum_{j} P_{j} \bar{E}_{j}^{i}+T^{i}
$$

Maximizing (2.1) subject to (2.2), (2.3) and (2.4) implies that a zero trade balance condition holds for each country.

In the customs union case, the two union members will jointly set an optimal tariff, and the third country will do so unilaterally. In the three-country Nash case, countries set optimal tariffs on all imported goods. The model we use assumes nothing about the direction of trade since this is endogenously determined as part of the equilibrium structure, and so only after trade directions are known do the pricing relationships in (2.2) apply.

In our computations, we use CES preferences for the utility functions (2.1), for which (in the CES case) utility maximizing demands are given by

$$
X_{j}^{i}=\frac{a_{j}^{i} I}{\left(P_{j}^{i}\right)^{\sigma^{i}} \sum_{j=1}^{3} \alpha_{j}^{i} P_{j}^{i\left(1-\sigma^{i}\right)}} \quad(i=1, \ldots 3)(j=1, \ldots 3)
$$




\subsection{Free Trade Competitive Equilibria}

In free trade equilibria, tariff rates are zero on all products in all countries. Given that only relative prices matter in such a structure, we can normalize prices to sum to unity in computing such equilibria, i.e.

$$
\sum_{j=1}^{3} P_{j}=1 ; \quad P_{j} \geq 0
$$

Equilibrium prices clear markets globally, i.e. equilibrium prices $\left(P_{1}^{*}, P_{2}^{*}, P_{3}^{*}\right)$ are determined such that

$$
\sum_{j=1}^{3} X_{j}^{i}\left(P_{1}^{*}, P_{2}^{*}, P_{3}^{*}\right)-\sum_{j=1}^{3} \bar{E}_{j}^{i}=0 \quad(i=1, \ldots, 3)
$$

and global excess demand are zero for each good.

\subsection{Three Country Non-Cooperative Nash Equilibria}

We also compute three-country non-cooperative Nash equilibria. In these, each country reacts to the other two countries' tariff setting and computes their own optimal tariffs. In the Nash equilibrium, country computations of optimal tariffs are mutually consistent ${ }^{3}$.

Specifically, in these cases each country determines their own optimal tariffs $\left(t_{j}^{i}\right)$ by maximizing $U^{i}$ subject to the constraint that global equilibrium in the three goods markets occurs. Each country maximizes $U^{i}$ subject to (2.2), (2.3) and (2.4), with the $\left(t_{j}^{i}\right)$ being endogenously determined. In these optimization problems, each country treats the other country tariffs as fixed, so that in the optimization the values of $\left(t_{j}^{i}\right)$ for $i \neq j$ are taken as given. These are denoted by $\hat{t}_{j}^{i}$.

In a Nash equilibrium optimal tariff rates $t_{j}^{i *}$ are such that

$$
t_{j}^{i *}=\hat{t}_{j}^{i} \quad \forall i, j
$$

and market clearing conditions hold

\footnotetext{
${ }^{3}$ See Johnson (1953-54) for computation of Nash equilibria for the two-country case where each country's best reply is independent of the other country' actions (constant elasticity offer surfaces) and Hamilton and Whalley (1983) for the two-country CES/Cobb-Douglas case.
} 


$$
\sum_{j=1}^{3} X_{i}^{j}\left(P_{1}^{*}, P_{2}^{*}, P_{3}^{*}, T^{* 1}, T^{* 2}, T^{* 3}\right)-\sum_{j=1}^{3} \bar{E}_{i}^{j}=0 \quad \forall i .
$$

A Nash equilibrium occurs in this structure when each country charges its optimal tariffs on imports given the tariffs set by other countries, country optimization is mutually consistent, and global markets clear. Market clearing, trade balance and optimizing behaviour on tariffs in each country thus define equilibria. Tariff revenues, $T^{i}$, also enter this version of the model, and affect demands since they are redistributed to the country's representative consumer in lump sum fashion. As above, no prior assignment of trade directions by product and by country is made.

\subsection{Customs Union Equilibria}

We also compute customs union equilibria using this structure. These are constrained Nash equilibria in which two of the three countries play cooperatively. Thus, if countries 1 and 2 form a customs union, they have zero tariffs between them and set a common external tariff against country 3 . We constrain the intraCU tariffs to be zero, and allow countries 1 and 2 to jointly set an optimal tariff against country 3 . Country 3 also sets an optimal tariff against the two country customs union. Countries 1 and 2 have a conflict of interest as to how their joint external tariff is set, and how they might best resolve this conflict has been the subject of previous research (see Kennan and Riezman, (1990)). Here, we simply assume that the joint external tariff is set to maximise the sum of country 1 and 2's utilities. Once again, the pattern of trade is not pre-specified.

The optimization problem for the members of the customs union (countries 1 and 2) is thus given as

$$
\max U^{1}+U^{2}
$$

subject to $(2.2),(2.3)$ and $(2.4)$ for each country, and the constraints on $t_{j}^{i}$ set out above.

In this mixed cooperative, non-cooperative structure, countries 1 and 2 set zero tariffs against each other, i.e. if the supplying country is 1 or 2 then

$$
t_{j}^{1}=t_{j}^{2}=0
$$

Implicit in this formulation is the assumption that members of the union receive the tariff revenues collected on their own imports from the third country. 
When a member country imports a good from both the member and non-member country, tariffs are only applied to the portion of imports coming from the nonmember country. For example, suppose countries 1 and 2 form a customs union, and in equilibrium country 1 imports good 2 from both countries 2 and 3 , in this case

$$
P_{2}^{1}=P_{2}^{2}=\left(1+t_{2}^{1}\right) P_{2} .
$$

The tariff $t_{2}^{1}$ is not directly applied to imports from country 2, in this case, only imports from country 3 . In computation we therefore need to determine bilateral trade flows.

\section{IMPLEMENTING THE APPROACH AND MODEL RE- SULTS}

To assess the frequency of trade pattern changes in comparisons across these equilibria for this model, we use a procedure of random draws on parameterisations of the model for preferences and endowments. Table 1 outlines the model structure we use in our calculations and other details of our procedures. These apply for pre-specified ranges of share parameters and elasticities in preferences, and also for endowments. ${ }^{4}$ We consider 2000 model parameterisations in our central case and later we do sensitivity analysis to allow for different numbers of random draws of parameter specifications and restrictions on the coverage of randomization (say, only for endowments).

\footnotetext{
${ }^{4}$ These ranges are between 0 and 1 for share parameters, with shares normalized to sum to one across goods for any country, between 0 and 1 for endowments of goods by country since relative endowments are what matter, and between 0.5 and 1.5 for substitution elasticities so as to yield a central tendency value of 1.0 (Cobb-Douglas).
} 
Table 1

Model Structure and Other Details of Experiments used to Assess the Frequency of Trade Pattern Changes

Dimensionality:

Preferences:

Endowments:

Number of cases:

Equilibria computed for

each case:
3 countries, 3 goods

CES, with parameter values generated

by random draws

Preference parameters and endowments

are randomly drawn from a unit interval

We consider 2000 different model

specifications in our central case, with

an equilibrium computed for each

Competitive equilibria, three-

country Nash equilibria, Customs

Union equilibria (the sum of member

utilities is maximized)

In these model formulations and unlike in theoretical work, the direction of trade in goods can change across equilibria, say between free trade and customs union equilibria. We endogenize trade direction changes in our computational analysis by modifying directional assumptions made in successive country optimization problems on the basis of what computed equilibria actually reveal. Specifically, any computation made as part of a sequence of calculations resulting in an equilibrium uses the last computation to yield the trade pattern assumption to be used in the next calculation. As computation progresses the trade pattern is allowed to change, and full equilibrium requires that the trade pattern does not change from one iteration to the next. In the competitive equilibrium case all that is required is that trade patterns be consistent from one calculation to the next, and markets clear. In the customs union and three country Nash cases, equilibrium requires that, in addition to trade pattern consistency, assumed and optimal tariffs must be the same for each country.

For free trade and customs union cases we are able to compute all equilibria for all model parameterisations generated by randomizations over the parameter space using these methods. We are, however, unable to compute three country Nash equilibria for approximately $17 \%$ of the model parameterisations we consider. In these cases solutions to country optimization problems settle on local rather than global optima and cycling occurs between such local solutions. In these cases, it is not possible to easily determine points on country reaction functions. There is no prior literature, to our knowledge, on computation of three-person Nash 
equilibria and hence previous discussion of the problem does not seem to exist. No problems of the type outlined above are encountered in the two- country case using our model solution code for Nash equilibria. Such cases are ignored in our calculation of frequency of trade direction changes.

Our results are shown in Table 2. They reveal significant sample frequencies for trade direction changes between free trade and customs union equilibria, as well as between three country Nash outcomes and these two equilibrium solutions. In $35 \%$ of the cases that we consider, at least one element of inter country trade changes sign between customs unions and free trade equilibria, and $40 \%$ of cases show similar changes between Nash and customs union equilibria. Between free trade and Nash equilibria, the direction of trade changes in about $21 \%$ of computed cases.

Table 2

Percentage Sample Frequencies for Trade Pattern Changes Equilibrium comparisons

1. Free trade and customs union Sample frequencies for trade pattern changes

2. Non-cooperative Nash and customs unions

3. Free trade and non-cooperative Nash

Table 3 reports on the sensitivity of our results to both different numbers of randomizations and restrictions on the coverage of randomizations. These indicate only small changes in the sample frequencies for changes in trade patterns. 


\section{Table 3}

\section{Sensitivity Analysis of Percentage Sample Frequencies for Trade Direction Changes}

\begin{tabular}{llll} 
& \multicolumn{2}{l}{$\begin{array}{l}\text { Percentage of Sample Frequencies for which } \\
\text { Trade Reversals Occur }\end{array}$} \\
& $\begin{array}{l}\text { Free trade } \\
\text { and CU }\end{array}$ & $\begin{array}{l}\text { Between Nash } \\
\text { and CU }\end{array}$ & $\begin{array}{l}\text { Free trade } \\
\text { and Nash }\end{array}$ \\
& 35.6 & 41.1 & 21.0 \\
$\begin{array}{l}\text { Central case } \\
\begin{array}{l}\text { Reducing the numbers of } \\
\text { randomizations to } 500\end{array}\end{array}$ & 35.3 & 41.9 & 18.8 \\
$\begin{array}{l}\text { Reducing the numbers } \\
\text { of randomizations to } 1000\end{array}$ & 37.3 & 40.8 & 21.7 \\
$\begin{array}{l}\text { Increasing the numbers } \\
\text { of randomizations to } 3000\end{array}$ & 36.0 & 40.6 & 20.2
\end{tabular}

Taken as a set, these results suggest that assumptions on pre-specified and unchanging trade directions usually made in theoretical analyses are difficult to justify for the model specifications we consider here. Trade direction changes seem to occur surprisingly frequently and extensively, and these can potentially undermine theoretical results generated by theoretical trade models analyzed with fixed directional assumptions.

\section{CONCLUSION}

In this paper we present computational evidence on the reliability of the assumption widely-used in the trade theory literature that the direction of trade by commodity and country remains unchanged as various comparative static exercises are undertaken. In a three-country three-good model, we compute free trade, customs union, and three-country Nash equilibria for a pure exchange model for a series of randomly generated parameterisations of the model. We find that in around $35 \%$ of free trade-customs union cases and in around $40 \%$ of customs 
union-three-country Nash cases trade patterns change, with comparisons showing: trade pattern changes in about $20 \%$ of free trade-three country Nash cases. Our conclusion is that the assumption of unchanged trade patterns, widely used in theoretical literature on geographically discriminatory trade agreements, has only weak computational support. 


\section{References}

Berglas, E. (1979), "Preferential Trading Theory: The $n$ Commodity Case". Journal of Political Economy 87, 315-331.

Hamilton, B. and J. Whalley (1983), "Optimal Tariff Computations in Alternative Trade Models and Some Possible Implications for Current World Trading Arrangements". Journal of International Economics 15: 323-48

Johnson, H.G. (1953-54), "Optimum Tariff Retaliation". Review of Economic Studies 21: 142-53.

Kehoe, T. (1980), "An Index Theorem for General Equilibrium Models with Production". Econometrica 48:1211-32.

Kennan, J. and R. Riezman (1988), "Do Big countries Win Tariff Warws?". International Economic Review 29: 81-85.

Kennan, J. and R. Riezman (1990), "Optimal Tariff Equilibria with Customs Unions". Canadian Journal of Economics 90: 70-83.

Kose, A. and R. Riezman, (2000), "Understanding the Welfare Implications of Preferenctial Trade Agreements". Review of International Economics, forthcoming.

Krugman, P. (1991), "Is Bilateralism Bad?". In Helpman, E. and E. Razin, International Trade and Trade Policy. Cambridge, Mass: MIT Press.

Lipsey, R.G. (1957), "The Theory of Customs Unions: Trade Diversion and Welfare". Economica 24: 40-46.

Lipsey, R.G. (1970), The Theory of Customs Unions: A General Equilibrium Analysis. London: Weidenfeld and Nicholson.

Lloyd, P.J. (1982), "A 3 x 3 Theory of Customs Unions". Journal of International Economics 12: 41-63.

Meade, J.E. (1955), The Theory of Customs Unions. Amsterdam: North-Holland.

Riezman, R. (1979), "A 3 x 3 Model of Customs Unions". Journal of International Economics 9: 341-354. 
Riezman, R. (1985), "Customs Unions and the Core". Journal of International Economics 19: 355-365.

Syropoulos, C. (1999), "Customs Unions and Comparative Advantage". Oxford Economic Papers 51: 239-66.

Viner, J. (1950), The Customs Union Issue. New York: Carnegie Endowment for International Peace. 